\title{
RENAL FUNCTION IN THE SEPARATE KIDNEYS OF MAN. II. HEMODYNAMICS AND EXCRETION OF SOLUTE AND WATER IN ESSENTIAL HYPERTENSION * $†$
}

\author{
By DAVID S. BALDWIN, WILLIAM H. HULET, $\ddagger$ ALBERT W. BIGGS,§ \\ ERVIN A. GOMBOS § AND HERBERT CHASIS \\ (From the Department of Medicine, New York University College of Medicine, and the Third
(New York University) Medical Division, Bellevue Hospital, New York, N. Y.)
}

(Submitted for publication July 8, 1959; accepted October 19, 1959)

The frequent coincidence of hypertension and renal disease is universally recognized, and it has been proposed that all hypertensive disease, including essential hypertension, somehow or other has its origin in the kidneys. This interpretation would be favored by the demonstration of one or more defects in renal function early in the course of essential hypertension. Although the presumed causal defect may, of course, be bilateral, the only feasible approach to this problem at the present time appears to lie in the functional comparison of the separate kidneys, which might reveal some subtle impairment not evident in bilateral studies.

In 1941, Chasis and Redish (1) examined 21 patients with essential hypertension by conventional methods and found that both kidneys were, grossly at least, equally affected. At that time, no data were available on the natural variability of function in the two kidneys of normotensive individuals. We have extended these observations by examining function in the separate kidneys, by ureteral catheterization, in 21 normotensive and 50 additional hypertensive subjects with respect to filtration rate, renal plasma flow, $\mathrm{Tm}_{\mathrm{PAB}}$, sodium, total solute and water excretion.

In the preceding paper (2) we have described the functional capacity of the separate kidneys in normotensive individuals and, in so doing, have defined a 'normal' limit of difference between the two kidneys for renal hemodynamics and sodium, solute and water excretion. The present study

* This investigation was supported in part by funds from the Abraham S. Birsh Fellowship Fund, the Joseph Laffan Morse Foundation and Grants H-3272 and H-1172 from the National Heart Institute, Bethesda, Md.

+ Presented at the Fifty-first Annual Meeting of the American Society for Clinical Investigation, May 4, 1959, Atlantic City, N. J.

$\ddagger$ Research Fellow, The American Heart Association. $\S$ Research Fellow, The New York Heart Association. compares the incidence of functional disparity in patients with essential hypertension to our normotensive group and also describes patterns of renal functional impairment which have been derived from correlating disparities in sodium and solute excretion.

\section{METHODS}

Observations were made in 50 patients with essential hypertension selected from the wards and outpatient clinic of the Third (New York University) Medical Division of Bellevue Hospital. Patients were chosen with minimal retinal and cardiac abnormalities according to heart X-ray, electrocardiogram and funduscopic examination, and the majority were judged to be in the early stage of essential hypertension. Patients known or suspected of having gross renal arterial or urologic disease were excluded.

The group consists of 43 female and 7 male patients between the ages of 14 and 65 years. All patients were maintained on the regular hospital diet. Fluids were withheld for 15 hours and the test was performed in the morning with the subjects in a fasting state.

Ureteral catheterization and the subsequent determination of filtration rate (GFR), renal plasma flow (RPF), $T_{m_{P A H}}$, and sodium, solute and water excretion $\left(U_{\mathrm{Na}} \mathrm{V}\right.$, $\mathrm{U}_{\mathrm{osm}} \mathrm{V}$ and $\mathrm{V}$ ) by the separate kidneys were performed according to the technique and methods outlined in the preceding paper (2). Calculations were made of sodium excretion fraction $\left(E F_{N_{2}}\right)$, solute excretion fraction $\left(\mathrm{EF}_{\mathrm{osm}}\right)$ and the per cent contribution of sodium and its attendant anion to the total urine osmolality $\left(U_{\mathrm{N} \Omega} i / U_{\text {osm }} \times\right.$ 100).

The data were examined to determine the incidence of disparities for each function according to the normal limits of difference between the two kidneys as established in the normotensive group.

\section{RESULTS}

Values for GFR, RPF, Tm $m_{\mathrm{PAH}}, \mathrm{V}, \mathrm{U}_{\mathrm{Na}}, \mathrm{U}_{\mathrm{osm}}$ and derived data in the separate kidneys of $50 \mathrm{hy}$ pertensive patients are presented in Tables $\mathrm{I}$ and II. Normal limits for disparate function are de- 


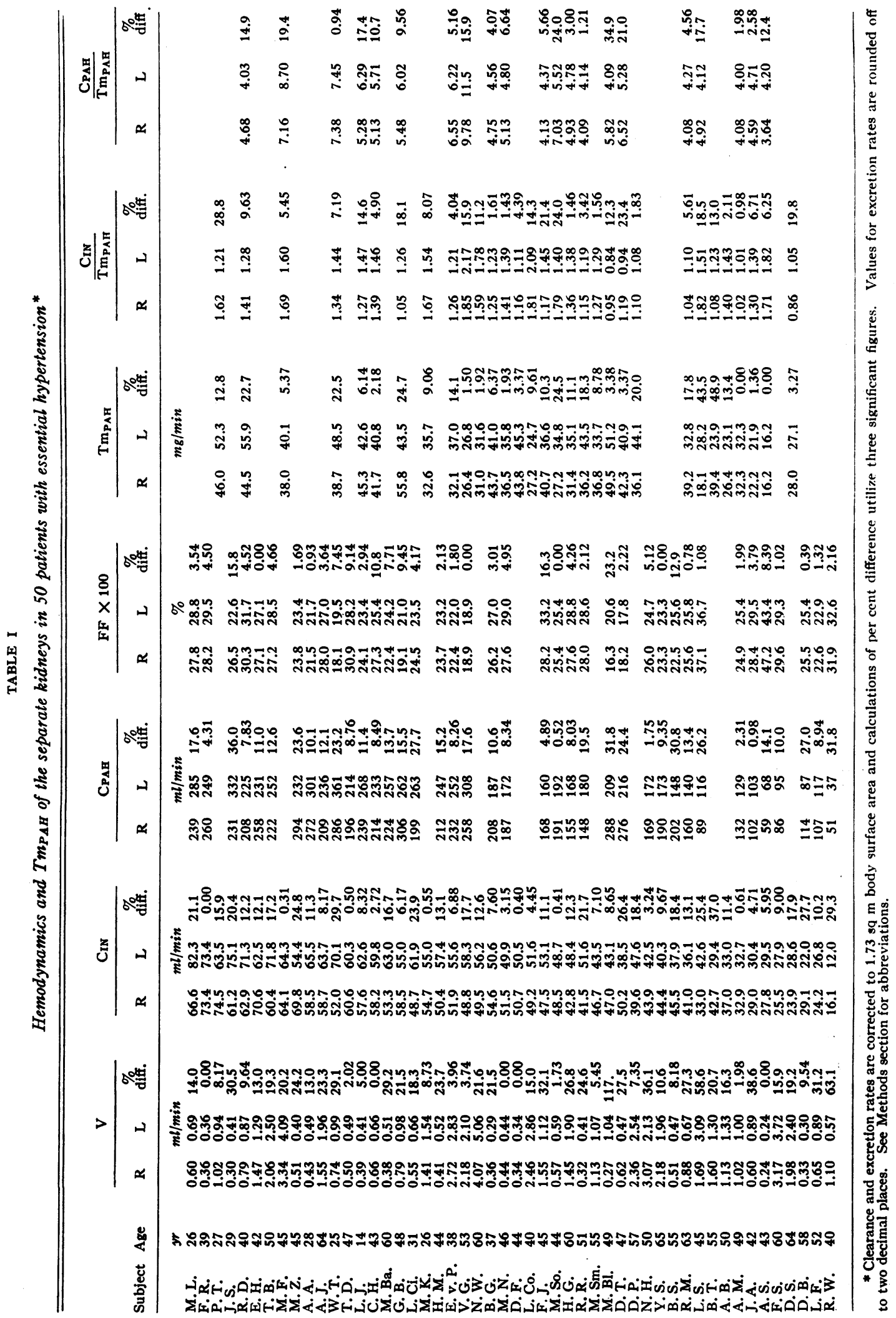




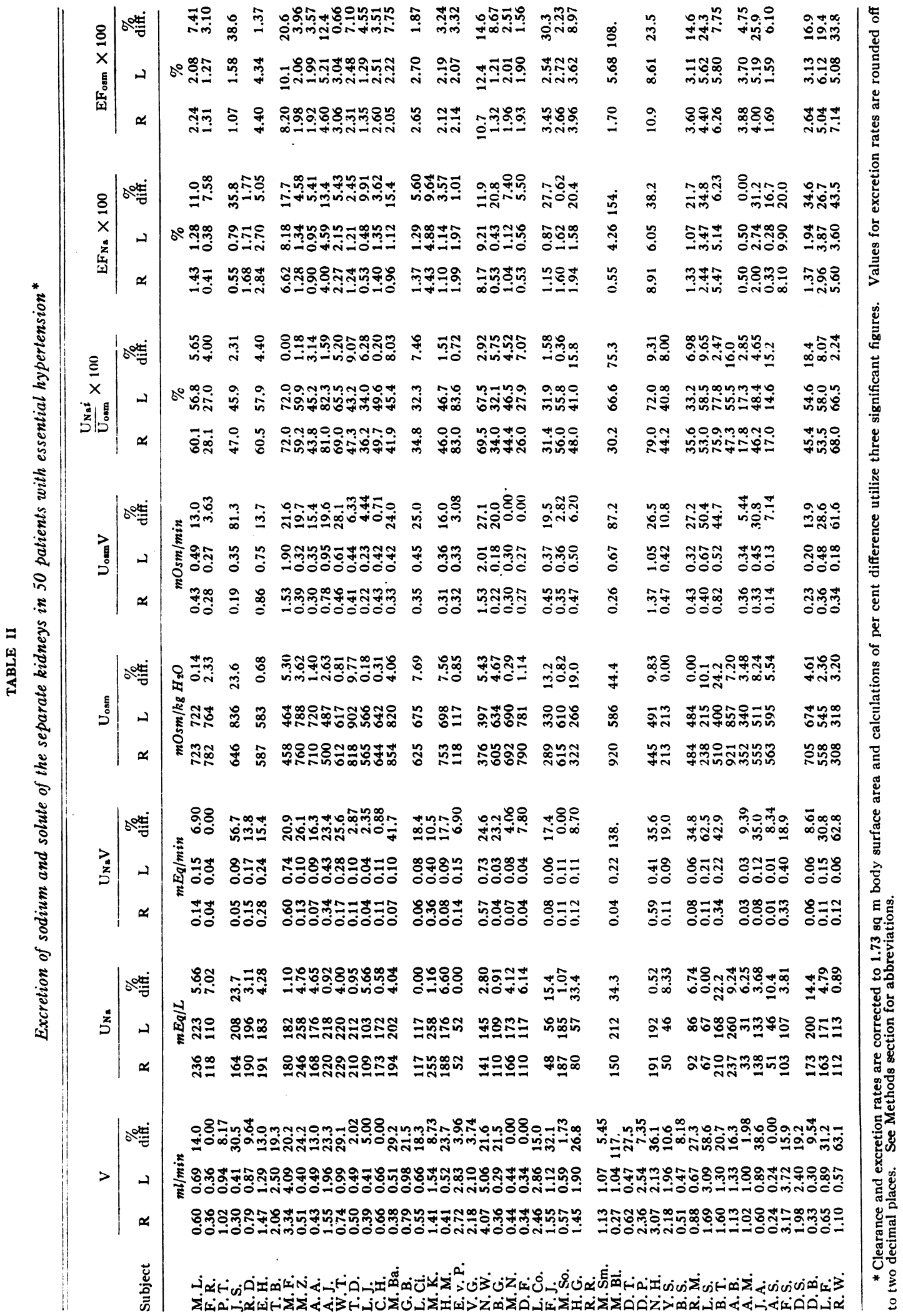


fined and evaluated clinically in our preceding paper on normotensive subjects (2).

Renal hemodynamics and T $m_{P A H}$. Disparity was observed with respect to: GFR, in 22 out of 50 patients; $R P F$, in 17 out of 36 ; and $T_{\mathrm{PAB}}$, in 13 out of 30 (Figure 1 ).

Filtration fractions were equal in the two kidneys in 32 of 36 patients, indicating that the mechanism that operates to elevate this function in hypertensive disease affects both kidneys equally. Equal filtration fractions were present in 13 of 17 patients with disparities in RPF, and may be attributed either to total loss of nephron function or to undisturbed relationship of efferent to afferent resistance in the presence of decreased blood flow to one kidney. Proportionally greater decrease in RPF than in GFR accounted for the disparate filtration fractions in the remaining 4 patients, suggesting increases in efferent resistance unilaterally.

The $R P F / \mathrm{Tm}_{\mathbf{P A H}}$ ratio was equal in the two kidneys in 13 of 19 patients, and the GFR/Tm $\mathrm{TAH}_{\mathbf{P A H}}$ ratio was equal in 19 of 30 patients. In the 6 patients with disparate $\mathrm{RPF} / \mathrm{Tm}_{\mathrm{PAB}}$ ratios, half had relatively greater ischemia in one kidney whereas the others had relatively greater loss in $\mathrm{Tm}_{\mathbf{P A H}}$. In the 11 patients with disparate GFR/Tm $\mathrm{T}_{\mathbf{P A H}}$ ratio, disproportionate reduction in $T_{m_{P A B}}$ was found in six.

In relating $\mathrm{RPF}$ to $\mathrm{Tm}_{\mathrm{PAH}}$, unilateral ischemia or hyperemia can be identified by comparison of the ratio, $\mathrm{C}_{\mathbf{P A H}} / \mathrm{Tm}_{\mathbf{P A H}}$, with the normal value of $6.10 \pm 1.10$ (SD), as determined in our unilateral studies in normotensive subjects. This ratio was within one standard deviation of the mean in both kidneys in 6 patients; decreased in 10 in both kidneys, indicating bilateral ischemia; and in 2 it was increased in both kidneys, indicating bilateral hyperemia. In 1 patient only (M.B1.) was unilateral ischemia present.

When the GFR/Tm $\mathrm{mAB}_{\mathbf{P A}}$ ratio exceeds the normal value of $1.27 \pm 0.25$ (SD), it may indicate the presence of "impotent" tubules. In only 2 instances were "impotent" tubules found in one kidney, while in 6 this ratio exceeded the normal in both kidneys, and in the remaining 22 the ratio was normal or depressed in both.

Urine concentration and excretion of sodium and total solute. Disparities in $\mathrm{U}_{\mathrm{Na}} \mathrm{V}$ were observed in 23 out of 38 patients and in $\mathrm{U}_{\text {osm }} \mathrm{V}$ in 22

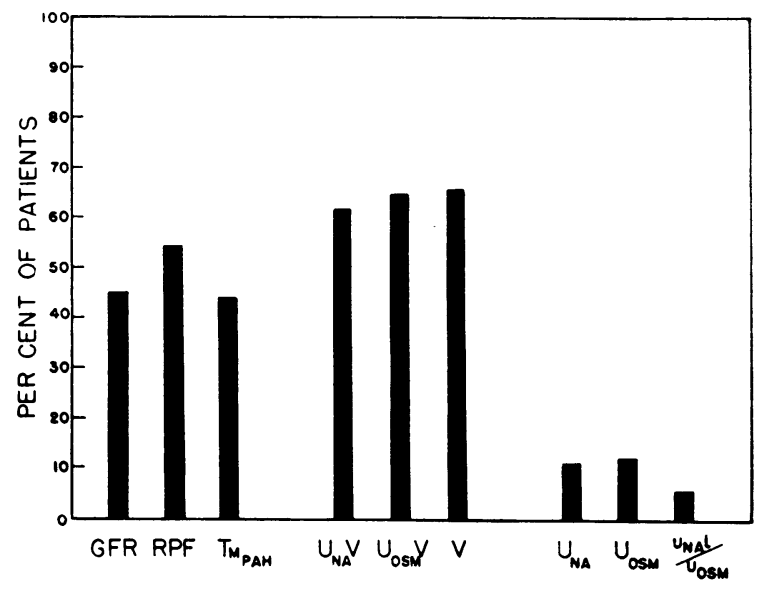

Fig. 1. InCIDENCE OF FUNCTIONAL DISPARITy BETWEen THE SEPARATE KIDNEYS IN 50 PATIENTS WITH ESSENTIAL HYPERTENSION.

out of 35 (Figure 1). The relationship of sodium to solute excretion was equal in the two kidneys in 34 of 36 patients, giving equal ratios for $\mathrm{U}_{\mathrm{Na}} i$ / $\mathrm{U}_{\mathrm{osm}}$ (Figure 1) over a wide range of $\mathrm{U}_{\mathrm{Na}} \mathrm{V}$ and $\mathrm{U}_{\text {osm }} \mathrm{V}$. The equality of this ratio was also maintained in 22 of 23 patients with disparities in $\mathrm{U}_{\mathrm{Na}} \mathrm{V}$ and $\mathrm{U}_{\mathrm{osm}} \mathrm{V}$. This suggests that $\mathrm{U}_{\mathrm{Na}} \mathrm{V}$ and $\mathrm{U}_{\mathrm{osm}} \mathrm{V}$ are affected alike by the functional disturbances which produced the disparities between the two kidneys.

$\mathrm{U}_{\text {osm }}$ was equal in the separate kidneys in 32 out of 36 patients and $U_{\mathrm{Na}}$ in 35 out of 39 (Figure 1), roughly indicating equal concentrating capacity of the two kidneys during moderate hydropenia. The data do not permit the accurate comparison of concentrating capacity since the protocol did not provide for prolonged hydropenia, controlled diet with respect to sodium and protein intake, or routine administration of Pitressin.

Urine volume. Disparities in volume (V) were observed in 32 out of 50 patients (Figure 1), and may be attributed to differences in solute loads or in urinary concentrating process. Values for $\mathrm{U}_{\text {osm }} \mathrm{V}$ are available in 25 of the 32 patients with disparities in $\mathrm{V}$; in $21, \mathrm{U}_{\text {osm }}$ was equal in the two kidneys, indicating that disparities in $\mathrm{V}$ primarily reflect disparities in solute excretion. In patients B.T. and J.S., unilateral decreases in both $U_{o s m}$ and $\mathrm{V}$ indicate diminished concentrating ability in the presence of reduced solute load. In H.G., reduction in $U_{\text {osm }}$ on the left with equal $U_{o s m} V$ in the two kidneys represents disparity in concentra- 
ting ability with equal solute loads. In patient M.Bl., $\mathrm{V}$ in the left kidney exceeded the right by 117 per cent while $U_{\text {osm }}$ on the left was 44 per cent less than on the right; this probably represents a decrease in $U_{o s m}$ resulting from excessive loading on the left rather than from impaired concentrating ability.

Comparison of parenchymal functions with sodium excretion. ${ }^{1}$ In 14 patients (Group A, Table III) filtration rate and $\mathrm{U}_{\mathrm{Na}} \mathrm{V}$ were equal in the two kidneys. T $\mathrm{m}_{\mathbf{P A H}}$ was disparate in 4 patients and may indicate unilateral impairment of PAH transport. The remaining 10 patients showed no evidence of unilateral renal impairment.

In 12 patients, despite equality in filtration rate, $\mathrm{U}_{\mathrm{Na}} \mathrm{V}$ was disparate; while in 5 patients $\mathrm{U}_{\mathrm{Na}} \mathrm{V}$ was equal but the filtration rate was disparate, giving 17 patients in whom $\mathrm{EF}_{\mathrm{Na}}$ was disparate (Table III, Group C).

Disparities in both filtration rate and sodium excretion were present in 19 patients, in 7 of whom the degree of disparity in sodium excretion exceeded that for filtration rate, giving disparities in $\mathrm{EF}_{\mathrm{Na}}$ (Table III, Group C).

In the remaining 12 patients, sodium excretion and filtration rate were reduced proportionally in one kidney, leaving the $\mathrm{EF}_{\mathrm{Na}}$ equal (Table III, Group B).

Thus, among these 50 hypertensive patients, 14 showed no disparity in either filtration rate or in sodium excretion (Group A). Twelve showed proportional disparities in filtration rate and sodium excretion, and hence equal $\mathrm{EF}_{\mathrm{Na}}$ (Group B), while 24 showed disproportional disparity with unequal $\mathrm{EF}_{\mathrm{Na}}$ (Group C).

The question now arises, can an abnormal kidney be identified by the sodium excretion fraction? To examine this point, the differences in sodium excretion. $\left(\mathrm{U}_{\mathrm{Na}} \mathrm{V}\right)$ may be plotted against those in filtration rate (GFR), both expressed as per cent of the mean bilateral value (Figure 2). Taking differences in GFR as the primary variable, differences in $\mathrm{U}_{\mathrm{Na}} \mathrm{V}$ are plotted as positive values when reduction in both $\mathrm{U}_{\mathrm{Na}} \mathrm{V}$ and GFR occur in the same kidney; differences in $\mathrm{U}_{\mathrm{Na}} \mathrm{V}$ are plotted

\footnotetext{
1 Since the ratio $U_{\mathrm{Na}_{\mathrm{a}}} i / \mathrm{U}_{\mathrm{osm}}$ was equal in all but two instances, reference is made only to sodium. In 11 of the 50 patients in whom data on $U_{o s m} V$ and $U_{N a} V$ are not available, $V$ has been considered to reflect these two functions, since in 35 of the 39 other patients $\mathrm{V}$ was found to vary with $\mathrm{U}_{\mathrm{Na}} \mathrm{V}$ or $\mathrm{U}_{\mathrm{osm}} \mathrm{V}$.
}

as negative values when the kidney with reduced GFR has a greater sodium excretion. Points that fall along the bisector represent equal $\mathrm{EF}_{\mathrm{Na}}$, and include patients with no disparity in either function (Group A, open circles) or equal reduction in both functions in the same kidney (Group B, triangles). Points that fall off the bisector represent patients with unequal $\mathrm{EF}_{\mathrm{Na}}$ (Group $\mathrm{C}$, solid circles). In all but three instances, the solid circles fall above the bisector because an excessive reduction in sodium excretion coincides with a lower filtration rate. This suggests that reduction in filtered load is primary and may serve to identify the kidney with the lower $\mathrm{EF}_{\mathrm{Na}}$ as the abnormal one. Since in three patients the kidney with the lower GFR had a greater $\mathrm{EF}_{\mathrm{Na}}$ (solid circles below the bisector), the possibility exists that an abnormal kidney may sometimes be characterized by a larger $E F_{\mathrm{Na}}$, as in $\mathrm{M}$. Bl., who showed an abnormally large sodium excretion on the left side.

\section{DISCUSSION}

Significant functional disparities between the two kidneys have been observed in 40 out of 50 randomly selected patients with essential hypertension.

The patients with functional inequality have been divided into two groups, according to whether there was equality or disparity between the two kidneys in the excretion fraction for sodium. Where there is equality in the $\mathrm{EF}_{\mathrm{Na}}$ of the two kidneys, we favor the explanation that there has been disparate total loss of nephron function so that tubular reabsorption of $\mathrm{Na}$ relative to filtered load remains unaltered in the kidney with proportionally reduced GFR and $\mathrm{U}_{\mathrm{Na}} \mathrm{V}$. The concept of disparate loss of total nephron function is strengthened by the fact that the lower GFR and $\mathrm{U}_{\mathrm{Na}} \mathrm{V}$ were frequently associated with proportional reduction in $C_{P A H}$ and $T_{m_{P A H}}$, giving equality of the ratios of $C_{I N}$ and $C_{P A B}$ to $T_{P A H}$ in the two kidneys. This explanation is not supported by the findings of Blake (3) in the dog in which complete cessation of flow to a portion of the nephrons by clamping a branch of the renal artery resulted in an overall increase in $G F R / \mathrm{Tm}_{G}$, $\mathrm{V} / \mathrm{GFR}$ and $\mathrm{C}_{\mathrm{osm}} / \mathrm{GFR}$, with a decrease in $\mathrm{U}_{\mathrm{osm}}$, which the author attributed to increased load delivered to the remaining functioning units. A possible explanation for this discrepancy may be found 


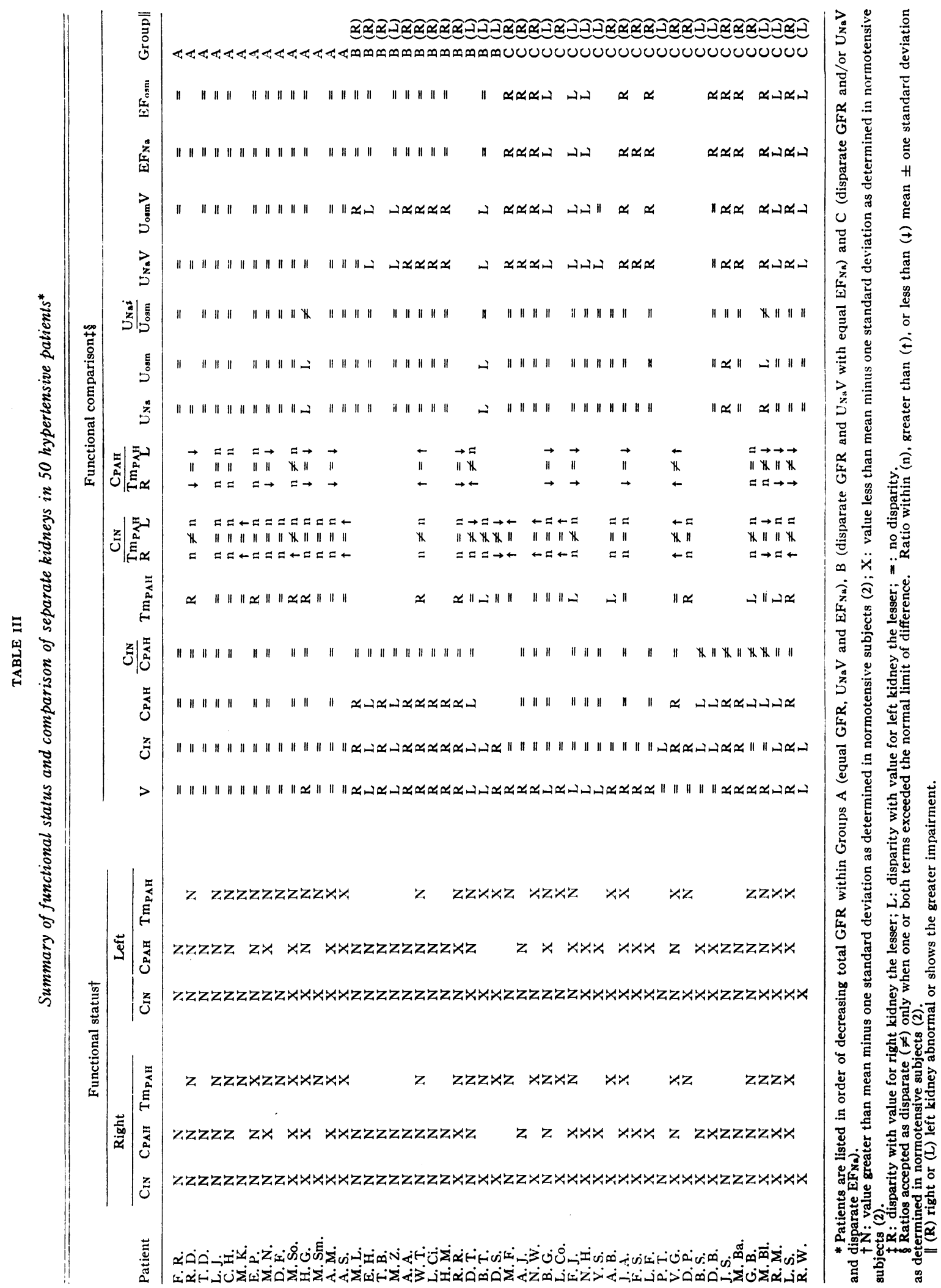


in the greater magnitude of the unilateral changes induced acutely by Blake in the dog as compared to the relatively lesser disparities observed by us in hypertensive patients.

Disparity in the $E F_{\mathrm{Na}}$ of the separate kidneys implies an alteration in the relationship of filtered load to tubular reabsorption of sodium. This might suggest the presence of a tubular defect in one or the other kidney, resulting in either excessive or reduced reabsorption of sodium. However, comparison of excretion fractions as a measure of tubular reabsorptive activity is meaningful only when filtered loads are equal (4). Since small decrements in filtered load of sodium result in disproportionate decreases in excretion rates (5, $6)$, it is necessary to compare the loads when differences in excretion fractions are encountered in the separate kidneys. When this comparison was made in our subjects we found that in most patients with disparities in $\mathrm{EF}_{\mathrm{Na}}, \mathrm{GFR}$ is lower in the kidney with lesser $\mathrm{EF}_{\mathrm{Na}}$. We have interpreted this as evidence that reduction in filtered load is primary and that this, rather than excessive reabsorption due to a tubular defect, accounts for the disparity in $\mathrm{EF}_{\mathrm{Na}}$ and identifies the kidney with lower $\mathrm{EF}_{\mathrm{Na}}$ as the abnormal one.

Where there is reduction in $\mathrm{EF}_{\mathrm{Na}}$, we favor the explanation that nephrons are present with reduction, but not cessation, of filtration, perhaps as a result of partial occlusion of the main renal artery or one of its subsidiary branches. Once again our hypothesis is not supported by the findings of Blake (3) when he partially occluded the main renal artery of one kidney in the dog, since he observed an increase in $U_{\text {osm }}$ under these conditions and attributed it to a reduced filtered load in all nephrons. However, our observations were made during hydropenia and at relatively low solute loads, and under these circumstances reduction in $\mathrm{U}_{\text {osm }}$ would not be anticipated from small reductions in filtered loads.

Only two of our patients were found to have functional disparities consisting essentially of decreased urinary volume and decreased urinary sodium and solute concentration in one kidney, the functional pattern which Connor, Berthrong, Thomas and Howard (7) have described as characterizing a kidney responsible for hypertension and which they have applied successfully in selecting patients for nephrectomy. Although both of

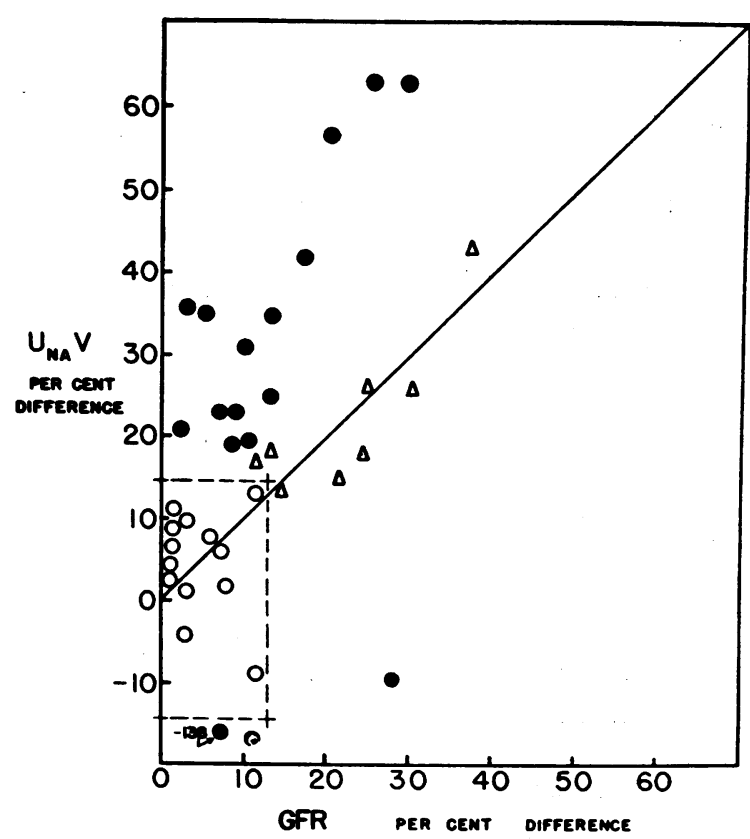

Fig. 2. RELATIONSHIP BETWEEN DIFFERENCES IN SODIUM EXCRETION AND DIFFERENCES IN FILTRATION RATE OF THE SEPARATE KIDNEYS IN 38 PATIENTS WITH ESSENTIAL HYPERTENSION. Taking difference in GFR as the primary variable, difference in $\mathrm{U}_{\mathrm{Na}} \mathrm{V}$ is plotted as a positive value when reduction in both is present in the same kidney, and as a negative value when the kidney with the reduced GFR has the greater $U_{N a} V$. Open circles (O) indicate patients with no disparity in either function and fall within the broken lines which represent the normal limits of difference. Triangles $(\Delta)$ indicate patients with equal reduction in both functions in the same kidney (equal $E F_{N_{a}}$ ) and hence fall along the bisector. Closed circles (O) represent patients with unequal sodium excretion fractions and fall off the bisector.

our patients were initially diagnosed as having essential hypertension, in one instance (L.J. ${ }^{2}$ ) the patient proved to have hyperaldosteronism, and in the other (J.S.) tubular calcification, colloidal degeneration and atrophy were present. In neither case was nephrectomy effective in reversing the hypertensive process. On the basis of this experience we suspect that a variety of disease processes can involve the kidneys unequally, and that

2 The initial observations on L.J. (Table II). showed no disparity between the two kidneys; however, serial observations over a three year period demonstrated progressive functional impairment in the right kidney consisting of decreased urine volume and urinary sodium and solute concentrations- $\mathrm{V}(\mathrm{ml}$ per $\mathrm{min}): \mathrm{R}=0.60$, $\mathrm{L}=1.05 ; \mathrm{U}_{\mathrm{Na}}(\mathrm{mEq}$ per $\mathrm{L}): \mathrm{R}=151, \mathrm{~L}=222 ; \mathrm{U}_{\text {。.m }}$ (mOsm per $\mathrm{kg} \mathrm{H}_{2} \mathrm{O}$ ) : $\mathrm{R}=584, \mathrm{~L}=633$. 
the functional pattern described by Connor and associates does not necessarily identify a kidney which is responsible for the hypertensive process. It seems unlikely, with out present techniques, that any particular pattern of renal functional disparity will prove to correlate consistently with the presence of a unilateral pressor mechanism. For this reason we are extending our comparison of the two kidneys in hypertensive patients to include additional functional parameters and a variety of experimental conditions.

The interpretation of quantitative functional impairment in terms of structural changes is subject to several limitations. For example, reduction in filtration rate may result from cessation of filtration due to loss of nephrons in local areas or from reduced filtration in nephrons more widely distributed. We have attempted to choose between these two possibilities by comparing the $\mathrm{EF}_{\mathrm{Na}}$ of the separate kidneys on the premise that proportional reduction in both $\mathrm{U}_{\mathrm{Na}} \mathrm{V}$ and GFR probably indicates loss of nephrons. This proved to be so in two-thirds of our patients with disparity in $\mathrm{GFR}$, while in the others reduction in $\mathrm{U}_{\mathrm{Na}} \mathrm{V}$ exceeded that for GFR, and we have concluded that here there has been reduction but not cessation of filtration in some nephrons. Proportional reduction in $\mathrm{Tm}_{\mathbf{P A B}}$ supported our concept of loss of nephrons in most instances; and equal $\mathrm{Tm}_{\mathrm{PAB}}$ in the separate kidneys was generally observed when we had concluded on the basis of unequal $\mathrm{EF}_{\mathrm{Na}}$ that there was reduction in filtration but not total loss of nephron function. However, values for $\mathrm{Tm}_{\mathrm{PAB}}$ do not necessarily provide a measurement of tubular mass, since reduction in $\mathrm{Tm}_{\mathrm{PAB}}$ may result from impairment of the transport system for $\mathrm{PAH}$ rather than from loss of functioning nephrons. Furthermore, hypertrophy of some nephrons may yield normal values for $T \mathrm{~m}_{\mathrm{PAB}}$ when there has been, in fact, diminution in the total number of nephrons.

Loss of nephrons may be obscured in functional measurements by hypertrophy of remaining nephrons in the same kidney, or comparison between the two kidneys may be affected by hypertrophy in one organ in response to impairment in the other, so that the observed functional differences may represent the sum of loss in one and hypertrophy in the other. Although compensatory hypertrophy can affect the degree of disparity between the two kidneys and the apparent extent of reduced function in one kidney, we attempted to minimize this factor by employing a method of comparison in which difference between the two kidneys for a given function is related to their mean value rather than the relation of right to left kidney.

The significance of disparities observed in the individual hemodynamic and excretory functions may be clarified by comparing the $\mathrm{C}_{\mathbf{I N}} / \mathrm{C}_{\mathbf{P A H}}$, $\mathrm{C}_{\mathrm{IN}} / \mathrm{Tm}_{\mathbf{P A H}}$, and $\mathrm{C}_{\mathbf{P A H}} / \mathrm{Tm}_{\mathbf{P A H}}$ ratios with normal values as well as by comparing the ratios in the separate kidneys. In the majority of our patients we found that $\mathrm{C}_{\mathrm{IN}} / \mathrm{C}_{\mathrm{PAH}}$ and $\mathrm{C}_{\mathrm{IN}} / \mathrm{Tm}_{\mathrm{PAB}}$ were increased over normal values and that $C_{P A B} / T_{m_{P A H}}$ was decreased, confirming the presence of an increase in relative efferent arteriolar resistance, impotent tubules, and relative ischemia in the hypertensive kidney (8). Generally, these ratios were equal in the separate kidneys, indicating that as the hypertensive process progresses, both kidneys, in respect to hemodynamics and tubular excretory capacity for $\mathrm{PAH}$, are affected qualitatively in a comparable manner. However, our present observation that disparity exists in the individual functional parameters demonstrates that quantitatively the two kidneys are affected to a different extent.

The validity of our results depends on accurate and complete collection of urine from the separate kidneys. Failure to collect all the urine from one or both kidneys due to leakage about the ureteral catheters could have particularly influenced the results in those instances in which we found proportional disparity in all parameters of renal function (Group B). Here the urine from the separate kidneys is qualitatively identical and the differences between the two depend solely on disparate urine volumes, a circumstance which might arise from incomplete urine collection. Disproportional reductions in filtration rate and sodium excretion (Group C) require that not only urine volume but also urinary concentrations vary between the two kidneys, so that leakage alone could not account for this type of disparity in function.

We have taken strict precautions for the prevention and detection of possible leakage of urine about the ureteral catheters. Large diameter, snugly fitting no. $8 \mathrm{Fr}$. catheters (no. 7 or $6 \mathrm{Fr}$. when the ureters could not accommodate the larger catheters) were inserted a distance of 12 to $16 \mathrm{~cm}$ 
from both ureteral orifices, and in all instances a soft rubber urethral catheter was left in place in the bladder. ${ }^{3}$ Constant or intermittent intravenous administration of phenol red or indigo carmine was performed so that leakage would readily be demonstrable by the appearance of any dye in frequently obtained bladder washouts. We have demonstrated repeatedly by this technique that the ureters can be effectively occluded, especially at low urine flows. Another method which we have used for the detection of leakage has been to inject dye into one of the ureteral catheters; appearance of color in the bladder irrigation not only indicates the presence of leakage but also identifies the side from which leakage is occurring. In the series reported here we have included no data obtained from studies in which any leakage occurred, except in the case of R.D., in whom the urine from the two kidneys differed qualitatively so that the origin of the leakage, i.e. left kidney, could be determined, and the appropriate correction in urine volume was made.

It appears that the techniques we have used for the collection of urine and detection of leakage are effective and reliable since repeat studies in many of our patients have consistently confirmed the results of earlier tests of separate kidney function in these same patients. This has proven to be so under a variety of experimental protocols and over a wide range of urine volumes. Furthermore, it is unlikely that leakage accounts for the high incidence of disparity between the two kidneys of the hypertensive patients as compared to the normotensive subjects, since both groups were studied under identical conditions.

Disparity in function between the two kidneys in essential hypertension may result from unequal involvement of the kidneys either by a hypertensive process of extrarenal origin, or, alternatively, by a disease of renal origin which is responsible for hypertension. $\mathrm{C}_{\mathrm{IN}}, \mathrm{C}_{\mathrm{PAH}}$, and $\mathrm{Tm}_{\mathrm{PAB}}$ were in the normal range for each kidney ${ }^{4}$ in 20 of the 50 hy-

\footnotetext{
3 In only 3 patients (M.F., G.B. and T.D.) was it necessary to perform the test utilizing urine from a ureteral catheter for one kidney and bladder urine for the other.

4 Function was considered reduced when the value was more than $1 \sigma$ below the mean obtained from unilateral observations in normotensive subjects- $C_{\text {IN }}, 57 \pm$ 7.1 (SD) $\mathrm{ml}$ per minute; $\mathrm{C}_{\mathrm{PAH}}, 261 \pm 60$ (SD) $\mathrm{ml}$ per minute; $T \mathrm{~m}_{\mathrm{PAB}}, 44 \pm 10.3$ (SD) $\mathrm{mg}$ per minute.
}

pertensive patients (Table III). Disparities between the two kidneys were found in 15 of these 20 , indicating that impairment was present in one kidney even though its hemodynamics were not diminished beyond the normal range. This demonstrates that a renal abnormality may be present early in the disease and is compatible with a renal origin of the hypertensive process. The incidence of disparities in the remaining 30 patients, who had reduction in renal hemodynamics, was no greater than in the 20 in whom these remained in the normal range ( 25 out of 30 in comparison with 15 out of 20), suggesting that a disparity which is present at the onset of essential hypertension may persist despite progressive involvement of both kidneys. Finally, failure to find disparity between the two kidneys need not exclude a primary renal role in the pathogenesis of essential hypertension, since the defect may be present to the same extent in both kidneys or may not affect the functions which we have examined.

\section{CONCLUSIONS}

1. Functional disparity between the two kidneys, exceeding that found in normotensive subjects, has been observed in 40 out of 50 patients with essential hypertension.

2. Disparity is present early in the disease.

3. Two patterns of disparity have been described. One suggests disparate total loss of nephron function; the other disparate decrease in filtration rate with consequent reduction in sodium excretion, or disparate reabsorption of sodium due to a tubular defect.

4. In view of the fact that a renal abnormality, as evidenced by functional disparity, is present early in the disease, the possibility exists that intrinsic renal disease may play a causal role in the genesis of essential hypertension. However, it is equally consonant with our data to believe that a hypertensive process not of renal origin may invade the two organs unequally.

\section{ACKNOWLEDGMENT}

The authors are grateful to Judy Oroszlan, B.S., and to Marilyn Hendy Smith, R.N., for their technical assistance throughout this study. 


\section{REFERENCES}

1. Chasis, H., and Redish, J. Effective renal blood flow in the separate kidneys of subjects with essential hypertension. J. clin. Invest. 1941, 20, 655.

2. Hulet, W. H., Baldwin, D. S., Biggs, A. W., Gombos, E. A., and Chasis, H. Renal function in the separate kidneys of man. I. Hemodynamics and excretion of solute and water in normal subjects. J. clin. Invest. 1960, 39, 000.

3. Blake, W. D. "Low pressure" kidney and the water concentrating mechanism (abstract). J. clin. Invest. $1958,37,878$.

4. Wesson, L. G., Jr. Glomerular and tubular factors in the renal excretion of sodium chloride. Medicine (Baltimore) 1957, 36, 281.

5. Mueller, C. B., Surtshin, A., Carlin, M. R., and
White, H. L. Glomerular and tubular influences on sodium and water excretion. Amer. J. Physiol. 1951, 165, 411.

6. Davidson, D. G., Levinsky, N. G., and Berliner, R. W. Maintenance of potassium excretion despite reduction of glomerular filtration during sodium diuresis. J. clin. Invest. 1958, 37, 548.

7. Connor, T. B., Berthrong, M., Thomas, W. C., Jr., and Howard, J. E. Hypertension due to unilateral renal disease-With a report on a functional test helpful in diagnosis. Johns Hopk. Hosp. Bull. 1957, 100, 241.

8. Goldring, W., Chasis, H., Ranges, H. A., and Smith, H. W. Effective renal blood flow in subjects with essential hypertension. J. clin. Invest. 1941, 20, 637. 